\title{
Isothiourea-Catalyzed Enantioselective Functionalization of 2-Pyrrolyl Acetic acid: Two-Step Synthesis of Stereodefined Dihydroindolizinones
}

\author{
Shuyue Zhang, James E. Taylor, Alexandra M. Z. Slawin, Andrew D. Smith* \\ EaStCHEM, School of Chemistry, University of St Andrews, North Haugh, St Andrews, Fife, KY16 9ST, U.K. \\ Supporting Information Placeholder
}
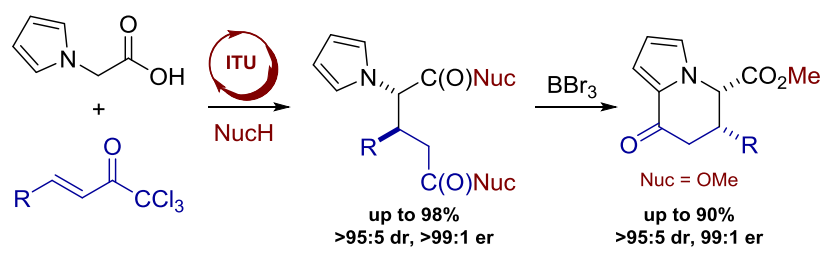

\begin{abstract}
Catalytic enantioselective functionalization of 2-pyrrolyl acetic acid with trichloromethyl enones using isothiourea catalysis is reported, leading to a range of stereodefined diesters and diamides after nucleophilic ring-opening with either methanol or benzylamine (30 examples, up to $>95: 5 \mathrm{dr}$ and $>99: 1 \mathrm{er}$ ). Subsequent intramolecular Friedel-Crafts reaction allows access to dihydroindolizinones in high yields and stereofidelity (6 examples, up to $>95: 5 \mathrm{dr}$ and 99:1 er)
\end{abstract}

Ammonium enolates generated from carboxylic acid derivatives are versatile reactive intermediates that can be used in a variety of stereoselective bond-forming processes. ${ }^{1}$ In this regard, isothioureas have emerged as powerful organocatalysts in a range of transformations proceeding via isothiouronium enolate intermediates. ${ }^{2}$ For example, the stereoselective intermolecular Michael addition-lactonization/lactamization of isothiouronium enolates with suitable $\alpha, \beta$-unsaturated enones or imines can be used to generate substituted dihydropyranones or dihydropyridinones, respectively, with excellent diastereo- and enantioselectivity. ${ }^{3}$ However, a current limitation of this methodology is the requirement for either an aryl, heteroaryl, or alkenyl substituent to be connected at the $\mathrm{C}(2)$ position of the arylacetic acid, with limited heteroatom tolerance at this position (Scheme 1a). $\alpha$-Nitrogenous substituents can be introduced with isothiouronium intermediates using either electrophilic $N$-acyl $N$-aroyldiazenes (Scheme 1 b), ${ }^{4 a}$ or via cooperative $\mathrm{Cu}$ catalysis using diaziridinones. ${ }^{4 \mathrm{~b}}$ To date, direct functionalisation of a carboxylic acid with an $\alpha$-nitrogenous substituent using isothiouronium enolates has yet to be reported. ${ }^{5}$ In this manuscript, the use of the pyrroloacetic acid 1 bearing an $\alpha-N$-pyrrole substituent as an isothiouronium enolate precursor is investigated (Scheme 1c). We envisaged that enantioselective Michael addition-lactonization with a masked $\alpha, \beta$-unsaturated ester equivalent, ${ }^{6}$ followed by nucleophilic ring-opening, would give $\mathbf{2}$ with high diastereo- and enantiocontrol. These products would act as valuable precursors in the preparation of functionalized dihydroindolizinones $\mathbf{3}$, using the inherent reactivity of the pyrrole unit to promote intramolecular Friedel-Crafts acylation. The indolizine core is widely found throughout Nature, ${ }^{7}$ while substituted dihydroindolizinones have been investigated for biological activity and used
Scheme 1. Scope and limitations of isothiourea-catalyzed enolate formation from carboxylic acid oxidation level

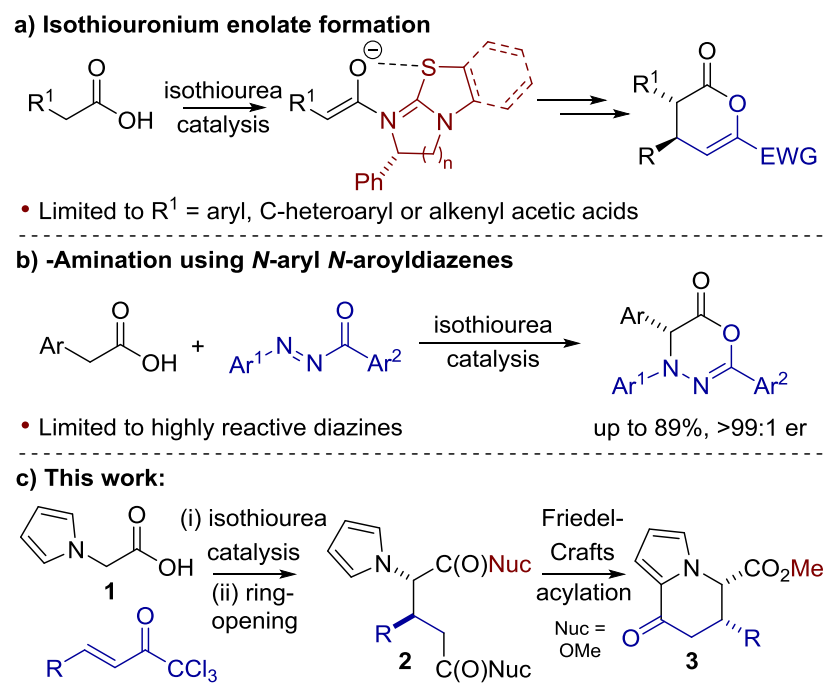

- Functionalization of pyrrolyl acetic acid - Access to dihydrindolizines

as versatile intermediates in natural product synthesis. ${ }^{8}$

Investigations began with the reaction of 2-(1H-pyrrol-1yl)acetic acid 1 with $(E)$-1,1,1-trichloro-4-phenylbut-3-en-2one 4 (Table 1). Treating acid 1 with pivaloyl chloride and $i$ $\mathrm{Pr}_{2} \mathrm{NEt}$ to generate a mixed anhydride in situ, followed by addition of the isothiourea BTM 7 (10 mol\%), trichloromethyl enone 4, and further $i$ - $\mathrm{Pr}_{2} \mathrm{NEt}$ in $\mathrm{CH}_{2} \mathrm{Cl}_{2}$ at $\mathrm{rt}$ led to exclusive formation of the pyranone $\mathbf{5}$, isolated in $50 \%$ yield (entry 1 ). The unexpected formation of $\mathbf{5}$ is thought to have arisen from 
base-mediated elimination of $\mathrm{HCl}$ from the desired dihydropyranone 6 followed by isomerization. ${ }^{9}$ The use of the isothiourea HyperBTM 8 as catalyst gave the first evidence of dihydropyranone $\mathbf{6}$. However, pyranone $\mathbf{5}$ was still the major product (entry 2). Screening showed that the reaction solvent has a dramatic effect on the product distribution, with both toluene and DMF leading to preferential formation of the dihydropyranone 6, albeit with a lower conversion of starting materials (entries 3 and 4). The use of ethyl acetate resulted in an $80 \%$ conversion into an $\sim 12: 88$ mixture of 5:6, with dihydropyranone 6 being formed in a promising $~ 89: 11 \mathrm{dr}$ (entry 5). Acetonitrile proved to be the optimal solvent, giving dihydropyranone 6 as the only product in $\sim 90: 10 \mathrm{dr}$ with quantitative conversion of the starting materials (entry 6). The use of alternative catalysts BTM 7 and tetramisole 9 led to lower reactivity, although the product ratio and diastereoselectivity remained high (entries 7 and 8). Lowering the catalyst loading of HyperBTM 8 to $5 \mathrm{~mol} \%$ resulted in a slight drop in product conversion (entry 9), while a control reaction in the absence of catalyst led to no product formation (entry 10). Unfortunately, all attempts to isolate product $\mathbf{6}$ by column chromatography or crystallization were unsuccessful. ${ }^{10}$

Table 1. Reaction optimization using pyrroloacetic acid 1

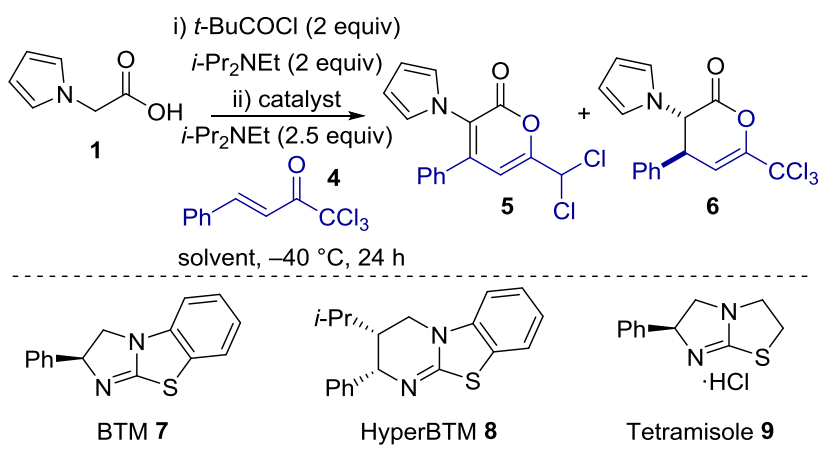

\begin{tabular}{|c|c|c|c|c|c|}
\hline entry & cat. $(\mathrm{mol} \%)$ & solvent & $\operatorname{conv}^{a}$ & $5: 6^{a}$ & $6 \mathrm{dr}^{a}$ \\
\hline $1^{b}$ & $7(10)$ & $\mathrm{CH}_{2} \mathrm{Cl}_{2}$ & $>99 \%$ & 100:0 & $\mathrm{n} / \mathrm{a}$ \\
\hline 2 & $8(10)$ & $\mathrm{CH}_{2} \mathrm{Cl}_{2}$ & $69 \%$ & $71: 29$ & $71: 29$ \\
\hline 3 & $8(10)$ & $\mathrm{PhMe}$ & $37 \%$ & $30: 70$ & $80: 20$ \\
\hline 4 & $8(10)$ & DMF & $40 \%$ & $15: 85$ & $91: 9$ \\
\hline $5^{c}$ & $8(10)$ & EtOAc & $80 \%$ & $12: 88$ & $89: 11$ \\
\hline 6 & $8(10)$ & $\mathrm{MeCN}$ & $>99 \%$ & $2: 98$ & $90: 10$ \\
\hline 7 & $7(10)$ & $\mathrm{MeCN}$ & $30 \%$ & $1: 99$ & $92: 8$ \\
\hline 8 & $9(10)$ & $\mathrm{MeCN}$ & $49 \%$ & $1: 99$ & $94: 6$ \\
\hline 9 & $8(5)$ & $\mathrm{MeCN}$ & $95 \%$ & $3: 97$ & $88: 12$ \\
\hline 10 & - & $\mathrm{MeCN}$ & $0 \%$ & $\mathrm{n} / \mathrm{a}$ & $\mathrm{n} / \mathrm{a}$ \\
\hline
\end{tabular}

${ }^{a}$ Determined by ${ }^{1} \mathrm{H}$ NMR analysis of crude reaction mixture. ${ }^{b}$ Reaction performed at rt. ${ }^{c}$ Reaction time $48 \mathrm{~h}$.

To facilitate the isolation of stable derivatives of the Michael addition-lactonization product $\mathbf{6}$, in situ ring-opening and nucleophilic displacement of the resulting $\mathrm{CCl}_{3}$ ketone was investigated (Scheme 2). Performing the HyperBTM-catalyzed Michael addition-lactonization reaction as previously, followed by addition of excess methanol and DMAP (20 mol\%) to the crude reaction mixture and warming to $\mathrm{rt}$ gave diester $\mathbf{1 0}$ as an 86:14 mixture of separable diastereoisomers isolated in $90 \%$ combined yield. Pleasingly, the major anti- diastereoisomer was formed in excellent 99:1 er, while the minor syn-diastereoisomer was obtained in 86:14 er. This process could be performed on gram-scale ( $8 \mathrm{mmol}$ 1) with $\mathbf{1 0}$ being isolated in comparable yield and enantioselectivity. ${ }^{11}$ Ring-opening with excess benzylamine followed by aminolysis was equally successful, giving diamide $\mathbf{1 1}$ in $70 \%$ yield as a single diastereoisomer after purification in 99:1 er. Secondary amines such as morpholine and pyrrolidine could also be used, giving products $\mathbf{1 2}$ and $\mathbf{1 3}$ in slightly reduced yields but high er (99:1).

Scheme 2. Ring-opening and $\mathrm{CCl}_{3}$ displacement ${ }^{a-c}$

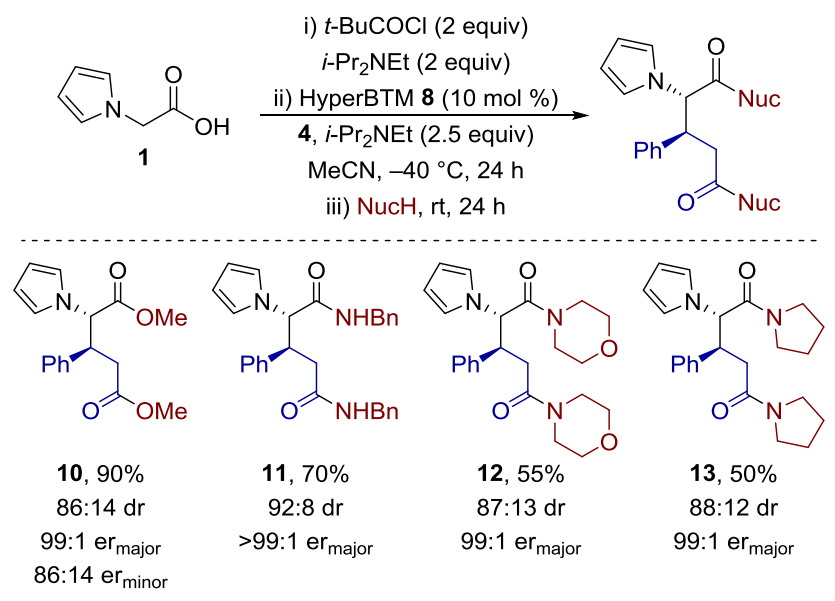

${ }^{a}$ dr determined by ${ }^{1} \mathrm{H}$ NMR analysis of crude reaction mixture.

${ }^{b}$ Combined isolated yield of separable mixture of diastereoisomers. ${ }^{c}$ er determined by HPLC analysis.

The scope of the developed methodology was further assessed by reacting pyrrole acetic acid $\mathbf{1}$ with various substituted trichloromethyl enones under the previously optimized conditions, followed by nucleophilic ring-opening and subsequent alcoholysis or aminolysis (Scheme 3). The reaction was tolerant of a range of aryl trichloromethyl enones, including those bearing electron-donating methoxy substituents, forming products 14-17 in good yield with excellent enantioselectivity. A range of electron-withdrawing substituents including 4trifluoromethyl and nitro-groups in each ring-position were also well tolerated, forming products 18-25 without compromising the stereoselectivity. Various halogen-substituted rings were also incorporated to form products 26-33 in excellent yield, with the major diastereoisomer in each case being formed in 99:1 er. The use of a 2-furyl-substituted trichloromethyl enone required an extended reaction time of $40 \mathrm{~h}$ to form the products $\mathbf{3 4}$ and $\mathbf{3 5}$ in good yields. The major diastereoisomer of diester $\mathbf{3 4}$ was successfully recrystallized and single-crystal X-ray analysis provided confirmation of the relative and absolute configuration, ${ }^{12}$ with all other products assigned by analogy. Alkenyl substituted trichloromethyl enones were also tolerated, allowing diester $\mathbf{3 6}$ and diamide $\mathbf{3 7}$ to be obtained in good yields and high er. However, alkylsubstituted trichloromethyl ketones gave products $\mathbf{3 8}$ and $\mathbf{3 9}$ obtained with low dr upon ring-opening. Notably, for each example, the diamide products resulting from aminolysis were consistently obtained with higher dr compared with the corresponding diesters from alcoholysis. Moreover, the minor diastereoisomeric diester product was obtained with lower er compared with the major diastereoisomer. For example, ringopening with $\mathrm{MeOH}$ gave diesters 26:40 in 80:20 dr, 

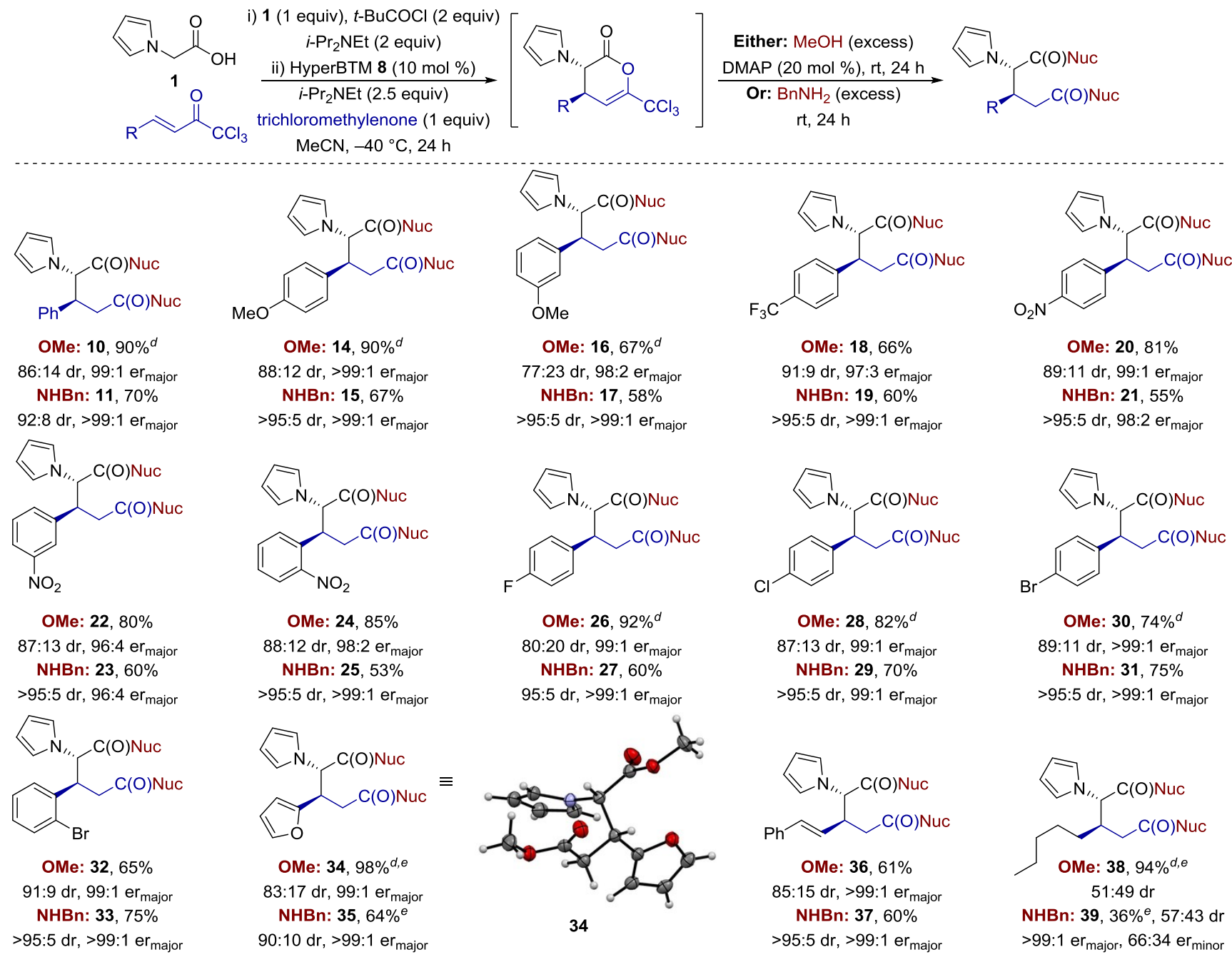

${ }^{a}$ Isolated yields of major diastereoisomer unless otherwise stated. ${ }^{b} \mathrm{dr}$ determined by ${ }^{1} \mathrm{H}$ NMR analysis of crude reaction mixture. ${ }^{c}$ er determined by HPLC analysis. ${ }^{d}$ Combined isolated yield of separable mixture of diastereoisomers. ${ }^{e}$ Reaction at $-40{ }^{\circ} \mathrm{C}$ for $40 \mathrm{~h}$.

with purification giving the separable major $(2 S, 3 S)$ diastereoisomer $26(99: 1 \mathrm{er})$, and the minor $(2 R, 3 S)$ diastereoisomer 40 (90:10 er). Control experiments (Scheme 4) treated isolated $(2 S, 3 S)-\mathbf{2 6}(>95: 5 \mathrm{dr}, 99: 1 \mathrm{er})$ with DMAP $\left(20 \mathrm{~mol} \%\right.$ ) and excess $i-\mathrm{Pr}_{2} \mathrm{NEt}$ in $\mathrm{MeOH}$, which resulted in selective epimerization at $\mathrm{C}(2)$, to give a 29:71 mixture of $(2 S, 3 S)-\mathbf{2 6}:(2 R, 3 S)-\mathbf{4 0}$, both in $99: 1$ er. ${ }^{13}$ Subjecting isolated $(2 R, 3 S)-\mathbf{4 0}(>95: 5 \mathrm{dr}, 90: 10 \mathrm{er})$ to the same conditions resulted in a similar $22: 78$ mixture of $(2 S, 3 S)-\mathbf{2 6}:(2 R, 3 S)-\mathbf{4 0}$, both in 90:10 er. These results suggest that epimerization of the major- $(2 S, 3 S)$-diester diastereoisomer gives the $(2 R, 3 S)$ diastereoisomer that is enantiomeric to that formed from ringopening and alcoholysis of the minor dihydropyranone diastereoisomer from the initial Michael addition-lactonization, accounting for the lower observed product er. An analogous experiment with diamide 27 showed no epimerization, consistent with the higher dr observed for this series. ${ }^{11}$

Next, the synthetic utility of the diester products as dihydroindolizinone precursors was investigated (Scheme 5). Treating isolated diester $\mathbf{1 0}$ with boron tribromide in $\mathrm{CH}_{2} \mathrm{Cl}_{2}$ at $0{ }^{\circ} \mathrm{C}$ resulted in a facile intramolecular Friedel-Crafts acylation to form the dihydroindolizinone $\mathbf{4 1}$ in $\mathbf{7 5 \%}$ yield without erosion
Scheme 4. Epimerization of diester products ${ }^{a, b}$

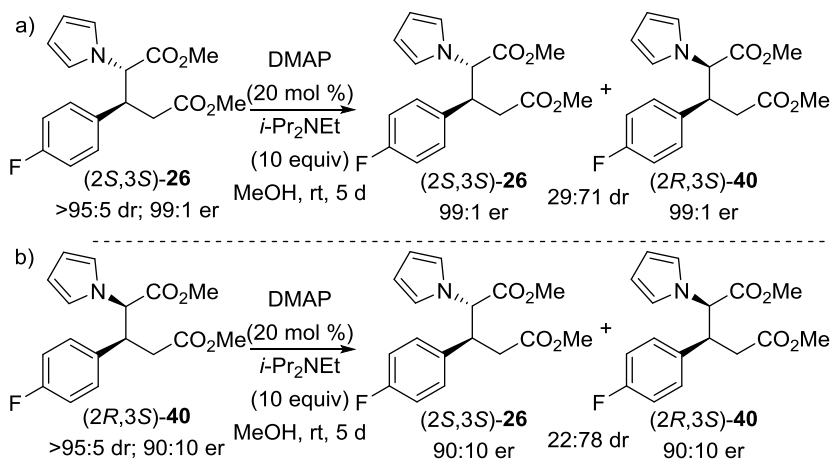

${ }^{a} \mathrm{dr}$ determined by ${ }^{1} \mathrm{H}$ NMR analysis of crude reaction mixture. ${ }^{b}$ er determined by HPLC analysis.

of either diastereo- or enantioselectivity ( $>95: 5 \mathrm{dr}, 99: 1 \mathrm{er}){ }^{14}$ Dihydroindolizinone derivatives $\mathbf{4 2 - 4 4}$ bearing electrondonating (4-OMe) and electron-withdrawing (4- $\mathrm{CF}_{3}$ and 4$\mathrm{NO}_{2}$ ) aryl substituents were prepared in an analogous fashion in high yield as single stereoisomers. A heteroaromatic 2-furyl 
substituent was also well tolerated, forming product 45 in excellent $86 \%$ yield. Chloro-substituted dihydroindolizinone 46 was also formed in high yield, with the relative and absolute configuration confirmed by single crystal X-ray analysis. ${ }^{15}$

Scheme 5. Synthesis of Dihydrindolizinones ${ }^{a-c}$

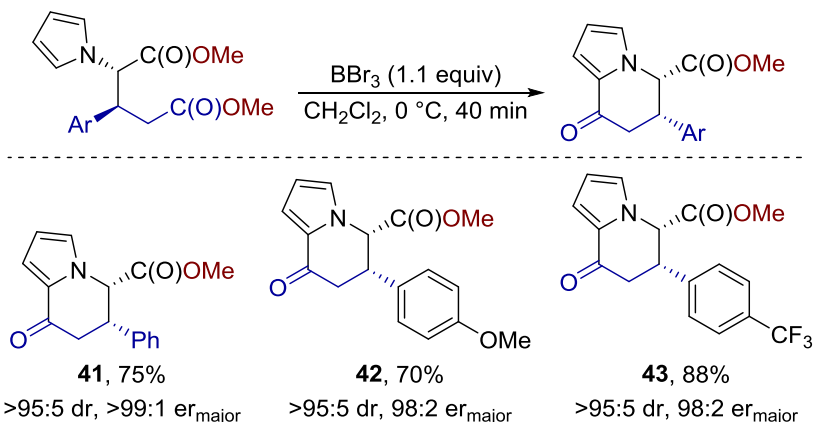<smiles>CC(=O)[C@H]1[C@@H](c2ccc([N+](=O)[O-])cc2)CC(=O)c2cccn21</smiles>

$44,80 \%$

$>95: 5 \mathrm{dr}, 98: 2 \mathrm{er}_{\text {major }}$<smiles>CC(=O)[C@H]1[C@@H](c2ccc(Cl)cc2)CC(=O)c2cccn21</smiles>

46, $90 \%$

$>95: 5 \mathrm{dr}, 99: 1 \mathrm{er}_{\text {major }}$

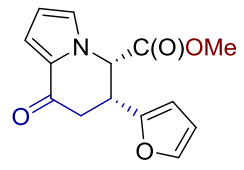

$45,86 \%$ $>95: 5 \mathrm{dr}, 98: 2 \mathrm{er}_{\text {major }}$

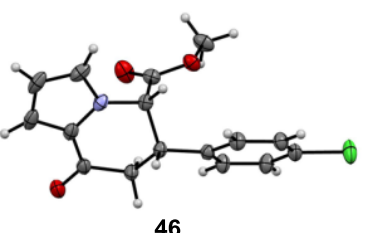

46
${ }^{a}$ Isolated yields. ${ }^{b}$ dr determined by ${ }^{1} \mathrm{H}$ NMR analysis of crude reaction mixture. ${ }^{c}$ er determined by HPLC analysis.

In conclusion, 2-(1H-pyrrol-1-yl)acetic acid $\mathbf{1}$ is a suitable isothiouronium enolate precursor, undergoing Michael addition-lactonization with a range of $\alpha, \beta$-unsaturated trichloromethyl enones. The dihydropyranone products readily undergo nucleophilic ring-opening followed by either alcoholysis or aminolysis to form substituted pyrroles with excellent diastereo- and enantioselectivity. These products can be further derivatized into substituted dihydroindolizinones through intramolecular Friedel-Crafts acylation.

\section{ASSOCIATED CONTENT}

\section{Supporting Information}

The Supporting Information is available free of charge on the ACS Publications website. Experimental procedures, ${ }^{1} \mathrm{H}$ and ${ }^{13} \mathrm{C}\left\{{ }^{1} \mathrm{H}\right\}$ NMR spectra, and HPLC traces for all novel compounds (PDF) Crystallographic data for 34, 40 and 46 (CIF)

\section{AUTHOR INFORMATION}

\section{Corresponding Author}

* E-mail: ads10@st-andrews.ac.uk

\section{Notes}

The authors declare no competing financial interest. The research data underpinning this publication can be found at doi.org/10.17630/3ba256ef-6b22-4165-9c14-56b0357b036a

\section{ACKNOWLEDGMENT}

JET thanks The Leverhulme Trust for an Early Career Fellowship [ECF-2014-005]. ADS thanks the Royal Society for a Wolfson Research Merit Award. We also thank the EPSRC UK National Mss Spectrometry Facility at Swansea University.

\section{REFERENCES}

(1) For reviews on the reactivity of ammonium enolates, see: (a) Gaunt, M. J.; Johansson, C. C. C. Chem. Rev. 2007, 107, 55965605. (b) Morrill, L. C.; Smith, A. D. Chem. Soc. Rev. 2014, 43, 6214-6226.

(2) For reviews on isothiourea catalysis, see: (a) Taylor, J. E.; Bull, S. D.; Williams, J. M. J. Chem. Soc. Rev. 2012, 41, 2109-2121. (b) Merad, J.; Pons, J.-M.; Chuzel, O.; Bressy, C. Eur. J. Org. Chem. 2016, 2016, 5589-5610.

(3) (a) Belmessieri, D.; Morrill, L. C.; Simal, C.; Slawin, A. M. Z.; Smith, A. D. J. Am. Chem. Soc. 2011, 133, 2714-2720. (b) Simal, C.; Lebl, T.; Slawin, A. M. Z.; Smith, A. D. Angew. Chem. Int. Ed. 2012, 51, 3653-3657. (c) Morrill, L. C.; Douglas, J.; Lebl, T.; Slawin, A. M. Z.; Fox, D. J.; Smith, A. D. Chem. Sci. 2013, 4, 41464155. (d) Morrill, L. C.; Ledingham, L. A.; Couturier, J.-P.; Bickel, J.; Harper, A. D.; Fallan, C.; Smith, A. D. Org. Biomol. Chem. 2014, 12, 624-636. (e) Morrill, L. C.; Smith, S. M.; Slawin, A. M. Z.; Smith, A. D. J. Org. Chem. 2014, 79, 1640-1655. (f) Smith, S. R.; Leckie, S. M.; Holmes, R.; Douglas, J.; Fallan, C.; Shapland, P.; Pryde, D.; Slawin, A. M. Z.; Smith, A. D. Org. Lett. 2014, 16, 25062509. (g) Yeh, P.-P.; Daniels, D. S. B.; Fallan, C.; Gould, E.; Simal, C.; Taylor, J. E.; Slawin, A. M. Z.; Smith, A. D. Org. Biomol. Chem. 2015, 13, 2177-2191.

(4) (a) Morrill, L. C.; Lebl, T.; Slawin, A. M. Z.; Smith, A. D Chem. Sci. 2012, 3, 2088-2093. (b) Song, J.; Zhang, Z.-J.; Chen, S.S.; Fan, T.; Gong, L.-Z. J. Am. Chem. Soc. 2018, 140, 3177-3180.

(5) Alternative methods such as organocatalytic phase-transfer catalysis using Schiff base $\alpha$-glycine derivatives is an established way of forming substituted $\alpha$-amino acids. For reviews, see: (a) Maruoka, K.; Ooi, T. Chem. Rev. 2003, 103, 3013-3028. (b) Najera, C.; Sansano, J. M. Chem. Rev. 2007, 107, 4584-4671. (c) Hashimoto, T.; Maruoka, K. Chem. Rev. 2007, 107, 5656-5682.

(6) (a) Zheng, C.; Li, Y.; Yang, Y.; Wang, H.; Cui, H.; Zhang, J.; Zhao, G. Adv. Synth. Catal. 2009, 351, 1685-1691. (b) Zhang, J.; Liu, X.; Ma, X.; Wang, R. Chem. Commun. 2013, 49, 9329-9331. (c) Morrill, L. C.; Stark, D. G.; Taylor, J. E.; Smith, S. R.; Squires, J. A.; D'Hollander, A. C. A.; Simal, C.; Shapland, P.; O'Riordan, T. J. C.; Smith, A. D. Org. Biomol. Chem. 2014, 12, 9016-9027. (d) Zhang, J.; Liu, X.; Wu, C.; Zhang, P.; Chen, J.; Wang, R. Eur. J. Org. Chem. 2014, 2014, 7104-7108. (e) Attaba, N.; Taylor, J. E.; Slawin, A. M. Z.; Smith, A. D. J. Org. Chem. 2015, 80, 9728-9739.

(7) Michael, J. P. Nat. Prod. Rep. 2008, 25, 139-165.

(8) (a) Dinsmore, A.; Mandy, K.; Michael, J. P. Org. Biomol. Chem. 2006, 4, 1032-1037. (b) Gracia, S.; Jerpan, R.; Pellet-Rostaing, S.; Popowycz, F.; Lemaire, M. Tetrahedron Lett. 2010, 51, 62906293. (c) Gerfaud, T.; Xie, C.; Neuville, L.; Zhu, J. Angew. Chem. Int. Ed. 2011, 50, 3954-3957. (d) Gao, A. X.; Hamada, T.; Snyder, S. A. Angew. Chem. Int. Ed. 2016, 55, 10301-10306. (e) Han, W. B.; Zhang, A. H.; Deng, X. Z.; Lei, X.; Tan, R. X. Org. Lett. 2016, 18, 1816-1819.

(9) An analogous elimination has previously been observed from $C(3)$-aryl substituted dihydropyranones, see ref. $6 \mathrm{c}$.

(10) Attempted chromatographic purification of 6 presumably leads to ring-opening with water to give the corresponding diacid derivative that cannot be isolated.

(11) See the Supporting Information for details. Attempted oxidative pyrrole deprotection of $\mathbf{1 0}$ led to a complex mixture of products.

(12) CCDC 1853444 contains the supplementary crystallographic data for diester 34.

(13) The relative and absolute $(2 R, 3 S)$-configuration of $\mathbf{4 0}$ was determined by $\mathrm{X}$-ray crystallographic analysis, with all other minor diastereoisomeric products assigned by analogy. CCDC 1853446 contains the supplementary crystallographic data for diester $\mathbf{4 0 .}$

(14) Amos, R. I. J.; Gourlay, B. S.; Molesworth, P. P.; Smith, J. A.; Sprod, O. R. Tetrahedron 2005, 61, 8226-8230. 
(15) CCDC 1853445 contains the supplementary crystallographic data for dihydroindolizinone $\mathbf{4 6}$. 